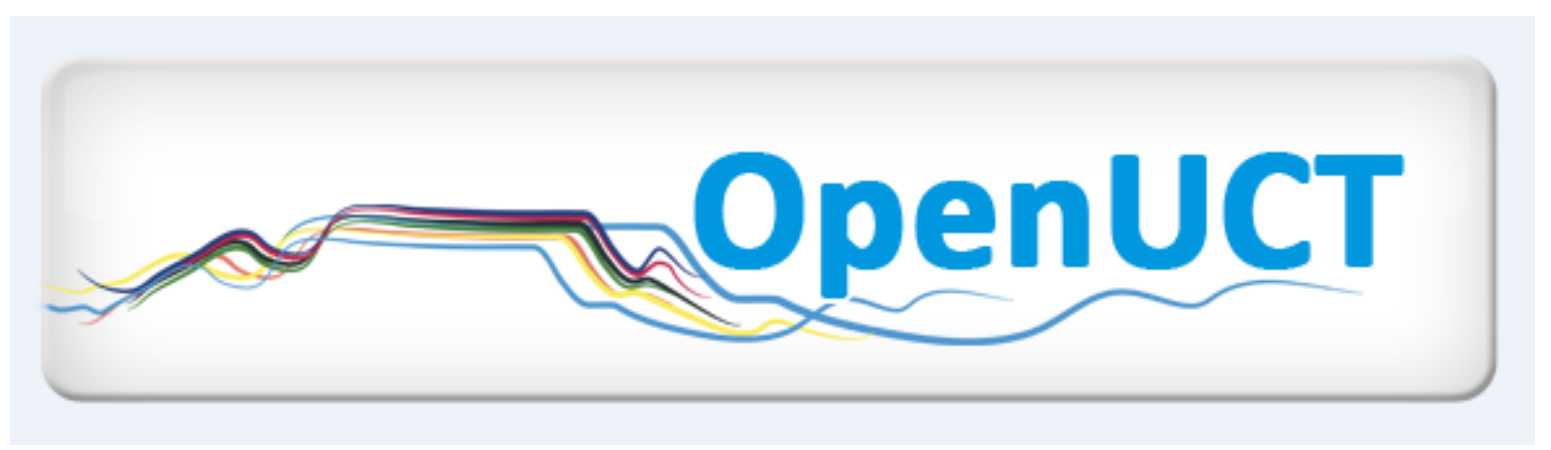

This is the post-print of Davidowitz, B. \& Potgieter, M. 2011. Preparedness for tertiary chemistry: multiple applications of the chemistry competence test for diagnostic and prediction purposes. Chemistry Education Research and Practice. (12): 193-204. DOI: 10.1039/C1RP90024B.

It is made available according to the terms of agreement between the author and the journal, and in accordance with UCT's open access policy available: http://www.openuct.uct.ac.za/sites/default/files/UCTOpenAccessPolicy.pdf, for the purposes of research, teaching and private study. 


\title{
Preparedness for tertiary chemistry: multiple applications of the Chemistry Competence Test for diagnostic and prediction purposes
}

\author{
Marietjie Potgieter and Bette Davidowitz \\ ${ }^{a}$ Chemistry Department, University of Pretoria, South Africa; e-mail: marietjie.potgieter@up.ac.za \\ ${ }^{b}$ Chemistry Department, University of Cape Town, South Africa; e-mail: Bette.Davidowitz@uct.ac.za
}

\begin{abstract}
The development of the Chemistry Competence Test was prompted by the extensive curriculum changes in the South African school system after democracy was established in 1994. As chemists, we were concerned that there might be a lack of articulation between secondary and tertiary levels, since we anticipated that curriculum changes would have an impact on the knowledge base and skills development of prospective students. A diagnostic test developed initially to document proficiencies of first-time entering students to South African universities has proved to be a versatile instrument for multiple uses. Apart from monitoring levels of preparedness for tertiary chemistry during a period of systemic change, it has also been used to evaluate institutional placement policies, to identify specific conceptual problems and procedural deficiencies, and to measure conceptual gains over the course of the first year at university. In addition, its application for the prediction of risk of failure in first-year chemistry based on cognitive and non-cognitive variables was demonstrated. All these findings are valuable resources to inform lecturers who are concerned about minimizing the conceptual gap between secondary and tertiary chemistry.
\end{abstract}

Keywords: Chemistry Competence Test, assessment, preparedness for tertiary chemistry, conceptual profile, conceptual gain

\section{Introduction}

An extensive revision of the national education system was undertaken after the establishment of a new democracy in South Africa in 1994. Outcomes-based education was introduced, and new curricula and syllabi were developed for primary and secondary education (DoE, 1998). These changes were phased in over a 13 year period, and it could be anticipated that there would be an impact on the level of knowledge and skills development of future students at tertiary level. The grade 12 class of 2008 was the first cohort of high school students who wrote the National Senior Certificate (NSC) examination, thus 2009 was the year in which this cohort, who were taught according to the new curricula within the outcomes-based education paradigm from Grade 1 to Grade 12, would have entered university. In order to ensure a smooth transition from secondary to tertiary education, first-year science curricula have to be aligned as closely as possible with those at secondary level. This generated the need for the development of a diagnostic instrument for the assessment of preparedness for tertiary chemistry. In this article we will describe the instrument and show how it was used over a period of eight years for multiple diagnostic as well as predictive purposes.

Our study is situated within the framework of constructivism (Ferguson, 2007), thereby acknowledging that students bring to the university existing knowledge structures into which new experiences must be integrated both by individual and social meaning making. The more informed lecturers are about the nature of students' prior knowledge and conceptual understanding, the better these educators would be able to design learning experiences that enable students to build scientifically sound concepts and modify unacceptable alternative conceptions. Lecturers also need to be informed about concepts that are especially challenging to assimilate, as well as the use of language and teaching tools that may impede rather than facilitate knowledge construction.

\section{The Chemistry Competence Test (CCT)}

Several test instruments have been described in the literature to assess proficiency in chemistry; some for diagnostic purposes (Russell, 1994; Mulford and Robinson, 2002) but the majority for selection and placement (McFate, and Olmsted III, 1999; Wagner et al. 2002; Toledo Chemistry Placement Exam of the Examinations Institute of ACS). Since we have undertaken to document the effect of the revision of the South African education system on preparedness for tertiary chemistry, we needed an instrument with content and face validity appropriate for the South African context. The instrument also had to have sufficient scope to provide the information that will do justice to the new physical sciencesı curriculum as well as the one that was replaced. Upon careful inspection none of the instruments cited above were deemed suitable for use without modification, but several proved to be a rich source of well-structured test questions. We therefore embarked on the development of a tailor-made aptitude test, combined with some elements of achievement testing (Altink, 1987) for the joint purposes of diagnosis and 
prediction, i.e. to serve as an indicator of preparedness for first-year chemistry and to optimise its predictive ability for either success or risk of failure in first-year chemistry. Preparedness for tertiary chemistry in our view does not consist only of content knowledge, but also of conceptual understanding of fundamental concepts assumed as pre-knowledge for tertiary chemistry. In addition, an appropriate level of mathematical and other skills, e.g. understanding of scientific terminology and representational competence, is required for mastery of chemistry at tertiary level.

The design criteria and performance of our instrument, called the Chemistry Competence Test, CCT, have been reported elsewhere (Potgieter et al., 2008a), but are briefly described here. For diagnostic purposes, coverage of fundamental concepts generally accepted as pre-knowledge in all subject topics included in a typical first-year chemistry syllabus was required (content validity). Conceptual questions were selected to assess a student's understanding of chemical ideas associated with a question, rather than algorithmic questions that can be answered by recall or application of practiced procedures (Bowen and

Bunce, 1997; Mayer, 2002). Representational competence was assessed, i.e. the ability to interpret symbolic, macro and submicro representations (Johnstone, 1993; Ainsworth, 2006) and questions assessing basic mathematical skills were included for their well-known predictive ability for success in first-year general chemistry (McFate and Olmsted, 1999; Wagner et al., 2002). Paired questions (two-tier methodology; Treagust, 1988) and pictorial representations were used in several cases. The majority of the 65 test questions that are included in the instrument were obtained from sources in the literature. Sixty questions are in multiple-choice format and the remainder require self-constructed responses, which are subsequently coded by the researchers.

The CCT instrument was piloted and refined through several cycles of implementation between 2003 and 2005 (Potgieter et al., 2005 ;

Potgieter et al., 2008a). All questions were carefully checked for clarity of presentation and language accessibility for second language speakers. The content validity of the instrument was rigorously assessed, and its high level of reliability was established by means of classical test theory (Cronbach alpha coefficients 0.80 and 0.83 ) as well as the Rasch measurement model (Bond and Fox, 2007). Rasch analysis of the data showed an item reliability of 0.99 and person reliability of 0.81 . The predictive ability of the CCT for performance in first-year chemistry compares well with non-South African placement tests and with Grade 12 mathematics performance; the latter is widely used for this purpose in South Africa (Potgieter et al., 2008a). Based on these statistical parameters the test instrument was judged to have performed according to expectations and remained unchanged during future rounds of implementation (from 2005 to the present). The scale of this study and the size of student samples precluded the use of methodologies typically associated with the constructivist paradigm, such as interviews, think-aloud protocols and discourse analysis (Ferguson, 2007). Instead, the study draws on the extensive documentation of alternative conceptions in chemistry (e.g. Barke, et al., 2009) that have been reported from this perspective, and seeks to present a holistic view of the relative prevalence of conceptual deficiencies across the landscape of general chemistry at the secondary-tertiary interface. In this paper we will present multiple applications of the CCT for both diagnostic and prediction purposes. Some of these applications have been reported previously; in these cases we include a summary of the findings to allow us to focus on aspects which have recently emerged from the data.

\section{Applications of the CCT for diagnostic and predictive purposes: a summary of earlier work}

\section{A. Monitoring levels of preparedness}

In a longitudinal study planned to stretch over a decade or longer the CCT is currently being used to document the proficiencies of first-year chemistry students upon entry to tertiary education. The mainstream B.Sc. cohorts of chemistry students at two tertiary institutions, University of Pretoria (UP) and University of Cape Town (UCT), were chosen for this purpose. Both these institutions have well-established chemistry departments, which are internationally recognised and attract some of the best students from throughout the country.

Baseline data collected at the start of the academic year in 2005 and 2007 at UP and UCT for students educated according to the former National Education curriculum (2005: NUP+UCT $=776 ; 2007$ : NUP+UCT $=760)$ formed the benchmark against which to measure shifts that occurred after introduction of the National Senior Certificate (NSC) in South Africa. Data collected in 2009 at UP $(\mathrm{N}=828)$ and UCT (N = 315) showed a decline in proficiency in all topics except Organic Chemistry, and significantly reduced skills development. The Rasch measurement model was used to provide a more accurate estimate of this decline in proficiency than was possible based on raw data. According to the Rasch model a 12 percentage point downward shift in preparedness occurred in 2009 compared with 2005 at these institutions (Potgieter and Davidowitz, 2010). This shift could be attributed mainly to a mismatch between the rating scales for mathematics of the NSC and those used previously, which allowed weaker students access to university. However, in addition to this factor, it was evident that the command of basic concepts, such as acids and bases and the mole concept, and skills development were considerably weaker than was documented for new first-year students in 2005. The process of curriculum refinement is ongoing, and we expect that the CCT will be useful for a number of years to provide feedback on the impact of curriculum refinement on student preparedness until the new education system has matured and a greater level of stability has been reached. 


\section{B. Evaluation of institutional placement policies}

The majority of South African tertiary institutions offer academic development (AD) programmes for prospective science and engineering students with good aptitude for science and mathematics who do not meet the entrance requirements for direct entry to the mainstream programmes. These $\mathrm{AD}$ programmes provide an opportunity for under-prepared students, usually from poorly resourced schools in townships or rural areas, to be educated for these national priority professions. In general, South African

mainstream study programmes do not provide explicit opportunities for the development of core academic competencies for success at tertiary level (Koch et al.,2001), whereas AD programmes are designed to develop both general and specific academic skills and provide counselling, support and career guidance (Grayson, 1996; Davidowitz and Schreiber, 2008; Lubben et al., 2010). Thus the placement of a borderline student in either mainstream or a development programme provides or denies access to support mechanisms that may be essential for the success of such a student.

By virtue of the fact that the CCT instrument was designed to measure preparedness for tertiary chemistry and has proven predictive ability for performance in first-year chemistry, it was considered to be suitable for application in a study aimed at the evaluation of tertiary placement policies. Ideally, mainstream students should perform significantly better on the CCT than those placed in AD programmes if placement policies were successful in the identification of under-prepared and at risk students. The

results of this study revealed distinctly different performance profiles for mainstream and AD cohorts respectively, at UCT and UP, but not at a third institution (University of Limpopo, UL) where mainstream students were only marginally better prepared than students in the AD programme, UNIFY, offered at that institution (Potgieter et al., 2008b). The majority of students placed in mainstream programmes at UL, therefore, did not have access to modules and support mechanisms in the UNIFY programme from which they could have benefited.

\section{Prediction of risk of failure in first-year chemistry based on cognitive and non-cognitive variables}

The CCT instrument was designed with the dual purpose of diagnosis and prediction of success or failure. Early identification of students at risk of failing first-year chemistry allows timely intervention. Cognitive factors alone are insufficient predictors for success; however, non-cognitive factors are usually difficult to measure. We have explored the use of accuracy of self-evaluation, an indicator of metacognitive ability, as a possible non-cognitive indicator for students at risk of failing the first semester course in General Chemistry at the University of Pretoria (Potgieter et al., 2010). Each of the multiple-choice questions in our CCT instrument is followed by a self-reported certainty of response indication, where students report their confidence in the correctness of their answers on a four-point Likert scale (certain, almost certain, not certain, a completely guessed answer). We assumed that students who stated that they were 'certain' or 'almost certain' that the answer was correct, expected that it would be, whereas students who chose 'not certain' or 'a completely guessed answer' expected that the answer would be wrong. Based on this assumption an expected score was calculated for each student.

Students should ideally be able to identify test questions for which they were not adequately prepared and express that in terms of a measure of uncertainty. However, in numerous studies over-confidence was found to be the norm rather than the exception, especially for academically weaker students (see Kruger and Dunning, 1999). It is well known that confidence judgments are often motivated by factors other than an objective appraisal of skills or mastery of content (e.g. Gramzow et al., 2003; Ehrlinger, 2008). Accuracy of self-evaluation, as measured by the difference between the actual and expected scores, was therefore, an accessible non-cognitive variable for inclusion in our statistical model for the prediction of risk of failing.

Variables with a strong correlation with performance in General Chemistry at the University of Pretoria were used to develop a prediction model based on logistic regression. For the purpose of statistical modelling, high risk students were defined as those with a final mark of $51 \%$ or lower for General Chemistry, where the minimum pass requirement is $50 \%$. Three variables, i.e. performance in mathematics and in physical science in the final school leaving examinations, and the extent of overconfidence expressed as the ratio between expected and actual performance in the CCT were shown to be significant predictors for risk of failing (Potgieter et al. 2010). The highest overall accuracy of prediction (76\%) was obtained for a subset of students with a C (60-69\%) or D grade (50-59\%) for their high school leaving examination in mathematics. The prediction model had a sensitivity of $92 \%$ (accuracy of prediction of high risk candidates) and a specificity of $46 \%$ (accuracy of prediction of low risk). The model's overall prediction accuracy compares well with those reported in literature, and its sensitivity of $92 \%$ towards high risk students is unmatched (Wagner et al., 2002). The model's low specificity is acceptable, since it is not intended to be used for placement purposes; instead it will classify a larger number of marginal students for remedial support, which will be to their benefit. This study has demonstrated that confidence judgments can be used successfully to strengthen statistical models for the prediction of students at risk of failing first semester General Chemistry.

\section{Latest findings from the CCT data: conceptual profiles and learning gains in first-year chemistry}

\section{Gaps in conceptual understanding and procedural skills - what is missing?}

The CCT has been custom-designed to probe the school-university interface in South Africa for the level of conceptual understanding of chemistry. It consists mainly of conceptual questions in a multiple-choice format, with known misconceptions presented as distractors 
(Bowen and Bunce, 1997). A careful analysis of the response frequencies for each of these questions would therefore enable us to determine the prevalence of known misconceptions (Barke et al., 2009; Duit, 2009) and construct a fairly comprehensive profile of conceptual understanding across the range of chemistry topics for which first-year lecturers would assume foundational knowledge to be in place. This profile will be especially useful within the South African context to assist first-year lecturers in responding in a meaningful manner to the changes that have occurred at secondary level, and to address the articulation gap that currently exists at the secondary-tertiary interface. It also contributes to a body of literature on basic chemical concepts that are often assumed to have been mastered when students arrive at university, but which often are not (for example Herron, 1975; Mulford and Robinson, 2002).

\section{Sample}

Five tertiary institutions were involved in 2009 in our study of the proficiencies of first-year chemistry students upon entry to university. Three of these were chosen for this study of conceptual deficiencies, i.e. UP, UCT and Stellenbosch University (SU). These universities are leading tertiary institutions in South Africa, which collectively draw some of the best talent amongst school leavers in South Africa. The pre-test performance results for their mainstream chemistry cohorts, therefore, represent the best case scenario of what the new educational dispensation in South Africa can produce in terms of preparation for tertiary chemistry. The three mainstream cohorts had similar profiles with respect to entrance requirements in 2009. All of the respondents in this sample qualified for admission to the mainstream programmes at their respective institutions. Data were collected at UP, UCT and SU as soon as possible after the start of the first semester; $N=828,315$ and 704 respectively.

\section{Data analysis}

The CCT consists of 65 questions of which 60 are multiple-choice, as was described above. The remaining five questions are in an open response format for which student responses were coded subsequently. The questions were divided into two subtests, each with 37 questions, including nine marker items that are common to both subtests. The response frequencies recorded for the 65 questions were analysed to identify incorrect answers or combinations of these, chosen or produced (in the case of open-ended questions) by more than $25 \%$ of each of the three cohorts in our sample. The choice of $25 \%$ as a threshold value would remove the influence of random guessing for all questions except one. This was a question where a threshold value of $33 \%$ was applied because only three possible answers were provided. Two-thirds of the questions $(\mathrm{N}=45)$ had a high enough incidence of incorrect answers to warrant detailed analysis. The two researchers carried out independent analyses of the distracters for each of these questions to gain insight into the misconceptions or lack of procedural understanding that gave rise to those choices, and formulated the descriptions reported in Table 1. Where a difference arose between the individual interpretations, the description or choice of distracters was determined by discussion and consensus was reached.

The conceptual problems and procedural deficiencies that emerged from this analysis are described in Table 1 . The designation of a and $\mathrm{b}$ to item numbers in the second column of Table 1 arises from cases where the distracters for more than one question allowed insight into the same or a similar misconception. In general, there was a small variation between the three institutions in terms of the prevalence of incorrect answers, hence we took an average to reflect the extent to which specific deficiencies were present (last column of Table 1). In our discussion of the findings reported in Table 1, we will focus on all items where, on average, more than $50 \%$ of students selected responses indicative of a specific conceptual problem (indicated in bold in the last column). These are grouped into several broad categories, which will be discussed below. In most cases these are important topics, which form the foundation of a first-year course in chemistry. Thus the CCT allowed us to identify gaps in the assumed pre-knowledge and baseline understanding of students who have qualified for admission to mainstream programmes at their respective institutions.

\section{Results and discussion}

\section{Stoichiometry}

Stoichiometry is usually one of the early topics covered in general chemistry text books (Brown et al., 2006; Silberberg, 2009) and forms the basis of other topics in the curriculum such as chemical equilibrium and electrochemistry. The data from the CCT reveal that students are confused about the meaning of co-efficients and subscripts for a balanced equation. Item 1a, the first entry in Table 1, requires students to determine the chemical formula of ammonium carbonate based on the formulae provided for sodium carbonate, ammonium chloride and sodium chloride. In order to answer the question students require an understanding of the rules of chemical nomenclature as well as being capable of logical reasoning (McFate and Olmsted, 1999). While students were able to identify the polyatomic cation and anion, almost $60 \%$ of students were not able to balance the charges in the formula.

\section{Balancing and interpreting chemical equations}

Mulford and Robinson's (2002) question probing the formation of sulfur trioxide from sulfur and oxygen using a submicro diagram was used to test students' understanding of balancing equations, stoichiometry and limiting reagents (items 2 and 3 ). The percentage of correct answers recorded for the three cohorts (between 15 and 21\%) was somewhat higher than the 11\% correct reported in the literature, but it is still 
Table 1 Description of conceptual problems and procedural deficiencies and their prevalence

\begin{tabular}{cccc} 
Categories & Conceptual problems and procedural deficiencies \\
number* & $\begin{array}{c}\text { Average } \\
\text { prevalence }\end{array}$ & UPUCTSU incorrect $)$ \\
$\mathrm{N}=828 \mathrm{~N}=315 \mathrm{~N}=704$ & $\%$ \\
\hline
\end{tabular}

Basic concepts

Stoichiometry

Mole concept

Inter vs

intramolecular

forces

Conservation of matter

$\begin{array}{ll}9 \mathrm{~b} & \begin{array}{l}\text { dense } \\ \text { Misconception: solution weighs less than solvent }+ \text { solute } \\ \text { Conservation of matter incorrectly applied to reactions: mass, atoms, molecules }\end{array} \\ 11 & \begin{array}{l}\text { Inability to predict periodic properties } \\ 12\end{array}\end{array}$

Periodic trends

12

Polyatomic ions in ionic compounds: inability to balance charges in formulae Polyatomic ions in ionic compounds: inability to combine charges in formulae Stoichiometry: confusion of coefficients $v s$ subscripts

Stoichiometry: no conservation of atoms

4 Confusion: mole $=$ molecule

5a Problem: Mole as a counting unit for atoms, molecules and ions

5b Problem: Mole as a counting unit for atoms, molecules or ions

\begin{tabular}{llll}
66 & 49 & 59 & $\mathbf{5 8}$ \\
40 & 47 & 37 & 41 \\
65 & 53 & 68 & $\mathbf{6 2}$ \\
70 & 66 & 61 & $\mathbf{6 6}$ \\
38 & 37 & 35 & 37 \\
45 & 51 & 44 & 47 \\
29 & 49 & 46 & 41 \\
& & & \\
43 & 35 & 40 & 39 \\
33 & 30 & 39 & 34 \\
35 & 33 & 35 & 34 \\
46 & 47 & 51 & $\mathbf{4 8}$ \\
38 & 47 & 43 & 43 \\
& & & \\
36 & 47 & 39 & 41 \\
45 & 42 & 44 & 44 \\
48 & 44 & 42 & 45 \\
60 & 57 & 57 & $\mathbf{5 8}$ \\
\hline
\end{tabular}

Special topics

Acids \& bases

13a Strong acid has strong bonds between components

$13 \mathrm{~b}$ Strong acid has strong bonds between components

14a Weak acid has weak bonds between components

$14 \mathrm{~b}$ Weak acid has weak bonds between components

Chemical

Equilibrium

17a For a saturated solution the concentration increases upon evaporation of solvent

$17 \mathrm{~b}$ Poor understanding of the concept of saturated solutions

18 Poor understanding of effect of pressure on reaction of gaseous substances

Electrochemistry $\quad 19$ Error: Conduction due to electrons (flowing) moving through the electrolyte solution

22 Structural representations misinterpreted (read carboxylic acid as alcohol)

Organic chemistry

23 Only $\mathrm{C}-\mathrm{C}$ bonds are covalent (ignore $\mathrm{C}-\mathrm{H}$ bonds in molecules)

24

\begin{tabular}{l}
\hline Process skills \\
\hline 3 level thinking \\
(macro, submicro \\
and symbolic)
\end{tabular}

25 Inappropriate notions of atomic size or Avogadro's $\mathrm{Nr}$

and symbolic)

Maths skills

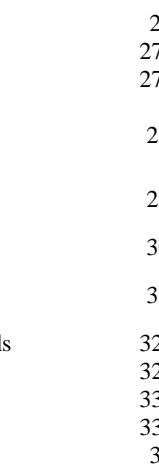

Particle nature of gases: poor concept of effect of temp change

Failure to interpret/analyse rusting as a chemical process (macro to submicro)

Failure to interpret/analyse rusting as a chemical process (macro to submicro)

Self-constructed drawing - 2 or 3 concepts wrong: incorrect dissolution of salts,

incorrect bonding in species or no conservation of matter

Inability to interpret scientific terminology, i.e. meaning of lowest whole number

29 ratio

Inability to interpret chemical terminology, i.e. compound name

30 Lack of formal reasoning in context of separation procedure / poor interpretation of information

Inability to handle numbers which include exponents: algebraic example

Inability to handle numbers which include exponents: algebraic example

Inability to handle problem which include exponents (example EM radiation)

Incorrect unit conversion for volumes
15 Acid-base reaction: Inability to identify conjugate acids and bases in a reaction

16 Hydrolysis of salts: inability to estimate the associated $\mathrm{pH}$

Redox reaction analysis: poor grasp of stoichiometry based on electron transfer

Redox reaction analysis: poor grasp of stoichiometry based on electron transfer

Incorrect application of oxidation numbers (assign and interpret)

Poor interpretation of structural representation (ester formed from aldehyde and alcohol)

Inability to handle numbers which include exponents (Avogadro's number)

\begin{tabular}{llll}
52 & 64 & 67 & $\mathbf{6 1}$ \\
41 & 45 & 49 & 45 \\
71 & 61 & 67 & $\mathbf{6 6}$ \\
51 & 51 & 54 & $\mathbf{5 2}$ \\
79 & 80 & 81 & $\mathbf{8 0}$ \\
73 & 73 & 76 & $\mathbf{7 4}$ \\
& & & \\
66 & 61 & 66 & $\mathbf{6 4}$ \\
80 & 82 & 78 & $\mathbf{8 0}$ \\
31 & 40 & 40 & 37 \\
59 & 50 & 59 & $\mathbf{5 6}$ \\
75 & 73 & 74 & $\mathbf{7 4}$ \\
74 & 78 & 80 & $\mathbf{7 7}$ \\
52 & 32 & 53 & 46 \\
69 & 58 & 68 & $\mathbf{6 5}$ \\
& & & \\
52 & 50 & 54 & $\mathbf{5 2}$ \\
31 & 31 & 33 & 32 \\
\hline
\end{tabular}

*Designation of $a$ and $b$ to item numbers arises from cases where the distracters for more than one question allowed insight into the same or a similar misconception. 
unacceptably low. Using the same combination of distracters as reported by Mulford and Robinson we observed similar trends when analysing the incorrect responses, namely, that $62 \%$ of students could not differentiate between the co-efficient and subscript for the product of the reaction, while $66 \%$ of students chose responses where conservation of atoms and/or reagents in excess was not taken into account. Many of these students visualised the product of the reaction as $\mathrm{S}_{2} \mathrm{O}_{6}$ instead of $2 \mathrm{SO}_{3}$. This type of misconception is persistent among first-year students, and requires active intervention from the lecturer to bring about conceptual change (Davidowitz et al., 2010).

\section{Acids and bases}

Ideas of acids and bases are fundamental concepts in chemistry curricula. Thus, it may come as a surprise that this topic is not given adequate prominence in the secondary school syllabus in South Africa. Students' difficulties in conceptualising acid-base equilibria have been documented, for example Kousathana et al., (2005), Drechsler and Van Driel (2008) Barke et al., (2009), and Duit (2009). Submicro diagrams are a very useful tool to probe students understanding of a particular concept (Davidowitz et al, 2010). Items 13 and 14 in Table 1 are based on submicro diagrams which were designed by Smith and Metz (1996) to probe students' understanding of strong and weak acids in terms of the extent of ionisation occurring in solution. For item 13, students were asked to choose which drawing best illustrated the concept of a strong acid, such as $\mathrm{HCl}$ in water. Just over $60 \%$ of students chose diagrams showing that all or most of the $\mathrm{HCl}$ entities had not undergone any ionisation (item 13a). When asked to explain their reason for their choice $45 \%$ of students chose either "A strong acid has a strong bond between its components" or "Strong acids are hard to dissociate (separate)" (item 13b). Item 14 was similar in format to item 13 and probed students understanding of the extent of ionisation of the weak acid, HF, in water. In this case two-thirds of students chose diagrams showing complete or almost complete ionisation of the acid, and when asked to explain their choice just over 50\% answered "The ions of weak acids are easily separated" or "Weak acids have a weak bond between its components". The performance of the students in this study was worse than that of the undergraduate chemistry students tested by Smith and Metz (1996), which is hardly surprising South African public schools.

Students' poor understanding of conjugate acids and bases was revealed by their answers to item 15, "In the reaction below, which species is (are) acting as an acid?"

$$
\mathrm{HPO}_{4}{ }^{-}+\mathrm{NH}_{4}{ }^{+} \leftrightarrows \mathrm{H}_{2} \mathrm{PO}_{4}^{-}+\mathrm{NH}_{3}
$$

$80 \%$ of students were unable to identify the acids which demonstrates that they had a very limited idea about Brønsted acids and did not conceptualise an acid-base reaction in terms of ions; a finding which had previously been reported by Nakhleh (1994).

Item 16 asked students to identify a series of cations based on whether solutions of their salts with simple anions were acidic, basic or neutral. To answer item 16, students would have to understand the concept of hydrolysis of cations, such as NH4+, as well as to be able to apply logical reasoning to complete a table provided. Just over a quarter of students were able to answer this question correctly, which is just above the level of a random guess. Students' difficulties in interpreting the hydrolysis of salts in aqueous solutions have also been reported by Furió-Más et al. (2007) who used a questionnaire to survey conceptual and procedural knowledge of acid-base behaviour of substances. The participants in their study were unable to interpret what happens to the ions when a salt dissolves in water i.e. they did not associate the hydrolysis of salts with proton transfer between cations or anions and water molecules.

\section{Chemical equilibrium: heterogeneous mixtures}

The concentration behaviour of saturated solutions was included in the set of questions probing understanding of chemical equilibrium. Students were asked to predict how the concentration of a saturated solution of sodium chloride would change if the water evaporated leaving a solutions that was half the volume of the original (item 17a). Almost two thirds of students did not realise that the concentration would remain constant. When asked the reason for their answer (item 17b), $80 \%$ chose "there is the same amount of salt in less water" or "salt does not evaporate and is left in solution". These findings are similar to those reported by Mulford and Robinson (2002), and reflect a lack of understanding of chemical equilibria of heterogeneous solutions.

\section{Electrochemistry}

Several researchers have identified electrochemistry as a difficult topic for students (Ogude and Bradley, 1994; Sanger and Greenbowe, 1997; Huddle et al., 2000). In the CCT, the topic was assessed using questions on conduction through electrolytes and oxidation-reduction reactions. In general, students' performance was poor which is in line with earlier studies reported for South African students (Ogude and Bradley, 1994; Huddle et al., 2000). Item 19 required students to complete the statement "In an electrochemical cell, conduction through the electrolyte is due to: ...". In response, $56 \%$ of students believed that conduction was due to "electrons moving across through the solution from one electrode to another". The notion of free electrons floating in the electrolyte was also the prevalent misconception identified by Ogude and Bradley among students at school and first-year university. Items $20 \mathrm{a}$ and $20 \mathrm{~b}$ were derived from two very similar questions. In one question students were given a balanced equation and asked to determine the number of moles of electrons transferred, while the other required students to balance the equation and to determine the sum of the co-efficients of the reacting and the product species. About three quarters of this cohort could not provide the correct answer to either of these questions. Since students were not asked to give a reason for their choice of answers, it is not clear 
whether the poor performance is due to a lack of understanding of the process of electron transfer in these reactions, or more fundamentally, a lack of understanding of the meaning of superscripts and co-efficients in balancing equations. Student difficulties in distinguishing between co-efficients and subscripts, symbols used routinely in chemical reactions, have previously been documented by Marais and Jordaan (2000). Assigning and interpreting oxidation numbers, item 21 , was also a problem for $46 \%$ of this cohort, who could not identify the species being oxidised in an equation describing the lead acid battery.

\section{Organic chemistry}

The curriculum for the new National Senior Certificate placed greater emphasis on organic chemistry than its predecessor; thus, it could be expected that students would master simple concepts such as recognising functional groups. While that was true in general, students' performance on items 22 and 23 was poor; for example, $68 \%$ of the cohort could not identify the two alcohols, given the structures of eight different compounds (Item 22). Many students believed that all compounds with a hydroxyl group are alcohols, including carboxylic acids. When presented with a group of structural formulae, just over half the students could not select the starting materials to synthesise an ester (Item 23).

\section{Representational competence}

Students need much more that an understanding of the concepts to achieve success in chemistry. Johnstone (1993) recommended that students should engage with material using 3-level thinking in the form of macro, submicro and symbolic representations, since these provide a useful framework for understanding and teaching chemistry. The submicro level is usually presented as diagrams where chemical entities are represented as circles, squares or other basic shapes. While expert chemists can easily interpret submicro diagrams, they present a significant challenge for the novice (Johnstone, 1993). There has been a steady increase in the use of submicro diagrams in text books both to explain the text and in the test banks at the end of the relevant chapters. In a recently published book, the authors argue for a coherent model for understanding the triplet relationship in chemical education based on reported research (Gilbert and Treagust, 2009). The examination paper for the NSC in 2008 included a question based on a submicro diagram, but it is not clear to what extent the teachers in South African schools make use of these in the classroom despite research showing that they are valuable teaching tools (Davidowitz et al., 2010).

The findings from the CCT show that students are not able to engage in 3-level thinking, as shown by their poor responses to items $25-28$. Two of these items ( 25 and 26) required interpretation of submicro diagrams, item 27 probed students' ability to move from the macro description of rusting to thinking at the submicro or molecular level, and for item 28 students had to construct a drawing of a solution of a mixture of two ionic compounds, given a key to the various components in the mixture. For item 25 , more than three quarters of students could not determine the approximate number of carbon atoms which, when placed next to each other, would make a line to cover a dot with a diameter of $2 \mathrm{~mm}$ (Mulford and Robinson, 2002). Almost $60 \%$ of students had a poor understanding of the effect of lowering the temperature from $20^{\circ} \mathrm{C}$ to $-5^{\circ} \mathrm{C}$ on the random motion of particles (item 26). Their choice of answers depicted the gas molecules as sinking to the bottom of the container, lining the walls of the container or grouped together in the middle of the container, which demonstrates that they do not understand the behaviour of gases at the molecular level. Item 27 a began with the statement, "Iron combines with oxygen and water from the air to form rust." Students were asked to choose an answer to complete the statement "If an iron nail were allowed to rust completely, one should find that the rust weighs ...". Just over $70 \%$ of students believed that the rust would be lighter or weigh the same as the nail from which it was formed, compared with a total of $46 \%$ of incorrect responses reported by Mulford and Robinson (2002) for the same question. When asked to explain their choice, about two thirds of students believed that rusting decreases the mass of the nail, the nail flakes away or that the mass of rust is less than the iron from which it was formed (item 27b). Misinterpretation of the macro level of thinking as demonstrated in this case would impact on understanding at the submicro and symbolic levels. Item 28 presented a precipitation reaction in symbolic format, and students were required to construct submicro representations of the reactants and products. The answers produced by $60 \%$ of the cohort either depicted the incorrect dissolution of the salts, incorrect association in terms of ionic species, or failed to take into account the conservation of atoms. Barke et al. (2009) also observed students' difficulties in representing ionic substances in solution.

The two items, 29 and 30, required students to interpret the symbolic language used routinely in chemistry. For item 29 , students were given the information that an empirical formula of a compound is the lowest whole number ratio of atoms in the molecule. Just over half of all students were not able to choose which of the molecular formulae presented to them could also be an empirical formula. Item 30 asked students whether they would support a petition to ban the substance, dihydrogen monoxide, based on a number of properties presented. The majority of students (ca. $70 \%$ ) voted to ban the substance, which implies that they considered only the reported properties of the substance and failed to recognise the name of the compound as the scientific name for water.

\section{Maths skills: handling exponents}

Chemists often deal in very small or very large numbers e.g. Avogadro's number. Being able to handle exponents and perform unit conversions are key skills required for stoichiometry and other calculations in the undergraduate curriculum. All the items grouped together as Maths Skills 
in Table 1 probe students' ability to handle exponents. Item 32 tested mathematical ability only, while item 33 consisted of two different examples which combined a logical or mathematical basis with a chemical context. Item 34 required a multi-step mathematical manipulation to convert a given volume from litres to cubic millimetres. The findings in Table 1 show that students in this cohort are not proficient at the simple mathematical skills required to solve problems in chemistry, and this will have an impact on their ability to carry out calculations related to stoichiometry and chemical equilibrium, among others.

\begin{abstract}
Miscellaneous
In addition to the gaps in conceptual and procedural understanding discussed above, Table 1 reveals that students do have difficulties in other areas. For example, when asked to predict which element in a given set would have chemical properties most similar to sulfur (item 12), $58 \%$ of students chose either phosphorus or chlorine. This demonstrates an inability to predict periodic properties. Students also had considerable difficulty in choosing the correct answer when questioned about the energetics of the reaction between gaseous hydrogen and oxygen to form water vapour (item 8). The responses to item 8 show that, on average, $48 \%$ of students believe that breaking of $\mathrm{H}-\mathrm{H}$ and $\mathrm{O}-\mathrm{O}$ bonds releases energy.

The analysis above presents a variety of misconceptions held by the incoming cohort of students at the start of their tertiary studies in chemistry in 2009. While the profile gleaned from the data presents a range of issues, we did not attempt to explore the relative prevalence of all known misconceptions. Nevertheless, there is enough material to provide a reasonably holistic conceptual profile on which lecturers can base their first-year teaching. We also did not use triangulation and qualitative methodologies to check the prevalence of conceptual and skills deficiencies as suggested by response frequencies in multiple-choice type questions in the CCT, but relied instead on work that has been reported during the past two decades in the research literature on misconceptions in chemistry.
\end{abstract}

\title{
E. Measuring learning gains in first-year chemistry
}

There is growing evidence that traditional modes (or methods) of instruction are limited in their ability to achieve conceptual development in science education, especially in large classes (DeHaan, 2005). Traditional instruction is loosely defined as that in which instructors "rely primarily on passive-student lectures, recipe labs, and algorithmic-problem exams" (Hake, 1998, p 65). First-year mainstream chemistry syllabi in South Africa are typically packed with a wide range of content topics. Lecturers often incorrectly assume that a certain measure of foundational knowledge and understanding is in place, and proceed to cover the new material, which is required as a foundation for follow-up courses in the undergraduate curriculum. Deficiencies in the understanding of basic concepts are seldom explicitly addressed, partly because of a lack of awareness by the lecturers, and partly because of the demands of an overcrowded syllabus. The question arises whether students would correct and consolidate their foundational conceptual understanding in the course of the first year in the absence of suitable intervention while having to master more advanced content material. Data collected for mainstream cohorts in 2009 were uniquely suited to cast light on this question. For example, first-year lecturers at South African universities who were aware that students had a much weaker foundation in acids and bases compared with previous years, could adjust their teaching accordingly. The learning gain achieved in the topic of acids and bases could, therefore, be viewed as a benchmark of what could reasonably be achieved when educators make the effort to address foundational conceptual problems during first- year mainstream teaching.

We were also interested in comparing the learning gains achieved in mainstream first-year chemistry with that achieved in AD programmes. At the Universities of Pretoria and Cape Town the teaching models used for academic development programmes differ markedly from the mainstream. Teaching and learning opportunities are specifically designed to address deficiencies in the level of preparedness of students entering tertiary science education both in terms of conceptual understanding and in terms of skills development. Traditional instruction as defined above is used less frequently, and classes are often converted into tutorial sessions that make provision for active engagement of students and immediate feedback by the lecturers involved. It could reasonably be expected that these $\mathrm{AD}$ programmes should be more effective in addressing conceptual and skills deficiencies than mainstream teaching, but such assumptions have not been investigated before.

The CCT, when used in a pre-test - post-test design, can provide information on learning gains in order to address the questions raised above. Data collected at the start of instruction and again close to the end of instruction before the final examinations provided information on entry and exit level performance on the CCT from which learning gain achieved during the first academic year was calculated. The parameter used for this purpose, "average normalised gain", $<\mathrm{g}>$, was defined by Hake (1998) for measuring conceptual gain in mechanics. Average normalised gain is the ratio of the actual average gain $\langle\mathrm{G}>$ to the maximum possible average gain, $\%<\mathrm{G}>$ max, i.e.

$\left.\left.\left.\langle\mathrm{g}\rangle=\%\langle\mathrm{G}\rangle / \%<\mathrm{G}>\max =\left(\%<\mathrm{S}_{\mathrm{f}}\right\rangle-\%<\mathrm{S}_{\mathrm{i}}\right\rangle\right) /\left(100-\%<\mathrm{S}_{\mathrm{i}}\right\rangle\right)$ where $\left\langle\mathrm{S}_{\mathrm{f}}\right\rangle$ and $\left\langle\mathrm{S}_{\mathrm{i}}\right\rangle$ are the final (post) and initial (pre) class performance averages, respectively. Hake has argued that this parameter can be applied over a range of diverse student populations, as it corrects for the variation in entry level proficiencies that may exist between different samples.

\section{Sample}

The 2009 mainstream cohort at SU and three different AD cohorts formed the sample for this study; two from UCT (2005 and 2007) and one from UP (2007). The CCT was administered as a pre-test in February and again as a post-test in September of a specific academic year. Table 2 reports descriptive data for these cohorts in terms of overall size, the number and size of lecture groups and organisation of contact time. The reported total weekly contact time takes into account small variations in the duration of lecture periods and practical sessions at the different institutions. The cohorts are further described in terms of entry and exit level performance on the CCT and average normalised learning gain. 
Table 2 Descriptive data and performance results for academic development cohorts at UP and UCT and the mainstream cohort at SU

\begin{tabular}{|c|c|c|c|c|c|}
\hline & & \multicolumn{4}{|c|}{$\begin{array}{l}\text { UCT UCT UPSU } \\
2005200720072009\end{array}$} \\
\hline $\begin{array}{l}\text { Nature of cohort } \\
\text { Size of cohort }\end{array}$ & $\begin{array}{l}\text { Pre-test } \\
\text { Post-test }\end{array}$ & \multicolumn{4}{|c|}{$\begin{array}{l}\text { ADAD AD Mainstream } \\
103106189704 \\
9878181620 \\
1165\end{array}$} \\
\hline \multicolumn{2}{|l|}{$\begin{array}{l}\text { Number of lecture groups } \\
\text { Number of students } \\
\text { per group }\end{array}$} & 103 & 106 & 32 & $150-200$ \\
\hline & $\begin{array}{l}\text { Lectures } \\
\text { Tutorials } \\
\text { Practicals } \\
\quad(2-3 \mathrm{~h}) \\
\text { Total time } \\
\quad \text { (min) } \\
\text { Pre-test }\end{array}$ & $\begin{array}{l}3 \\
2 \mathrm{a}\end{array}$ & $\begin{array}{l}3 \\
2 \mathrm{a}\end{array}$ & $\begin{array}{l}0 \\
4 \mathrm{~b}\end{array}$ & $\begin{array}{c}3 \\
1 \mathrm{c} \\
0.5 \mathrm{c}\end{array}$ \\
\hline Avg. Performance (\%) & Post-test & $\begin{array}{l}39 \\
52 \\
22\end{array}$ & $\begin{array}{l}35 \\
46 \\
17\end{array}$ & $\begin{array}{l}36 \\
51 \\
24\end{array}$ & $\begin{array}{l}41 \\
48 \\
12\end{array}$ \\
\hline $\begin{array}{l}\text { a Students were divided } \\
\text { supervised by lecturer } \\
\text { b Lecture periods were or } \\
\text { a tutorial } \\
{ }^{c} 40 \% \text { of the weekly } 3-h o \\
\text { tutorial sessions, which } \\
\text { tutorial period. }\end{array}$ & $\begin{array}{l}\text { mall group } \\
\text { as a blend } \\
\text { tical sessio } \\
\text { to the tim }\end{array}$ & $\begin{array}{l}\text { ach lec } \\
\text { a trad } \\
\text { t SU } \\
\text { uival }\end{array}$ & $\begin{array}{l}\text { a tu } \\
\text { nal le } \\
\text { o cor } \\
\text { of a }\end{array}$ & $\begin{array}{l}\text {, ses } \\
\text { ure a } \\
\text { erted } \\
\text { ekly }\end{array}$ & \\
\hline
\end{tabular}

\section{Data analysis}

In order to obtain a detailed picture of the learning gains in mainstream chemistry at SU, the pre-test and post-test response frequencies of the SU cohort were analysed according to the conceptual profile described in Table 1 . The prevalence of conceptual and procedural deficiencies in pre- and post-test data is reported in Table 3 using the same numbering system as Table 1. The percentage gain is expressed as a percentage of absolute gain (the difference between post-test and pre-test values) relative to the pre-test prevalence. Negative values for percentage gain reflect a reduction in the prevalence of deficiencies, i.e. an improvement, and positive values signal a deterioration of understanding or skills development. A threshold value of $24 \%$ gain was heuristically chosen above which learning gain was considered to be meaningful. This choice is informed by the distribution of gain values in Table 3 and a consideration of what tertiary educators could expect to be achieved during a full academic year. For example, a reduction of the prevalence of conceptual item 1a from $59 \%$ to $40 \%$ (-32\% gain) is meaningful, whereas a reduction from $68 \%$ to $61 \%$ (item 2 ) or an increase from $35 \%$ to $40 \%$ (item 4 ) is not.

\section{Discussion}

The normalised overall learning gain recorded for the SU mainstream cohort was $12 \%$ as compared to gains between 17 and $24 \%$ for the AD cohorts in this study (Table 2). It is clear from the descriptive data reported in Table 2 that the amount and organisation of weekly contact time was comparable for all the cohorts, but the size of lecture groups varied considerably between the different programmes. In general, the smaller the size of lecture groups the higher the learning gain that was recorded. An important factor influencing learning gain as measured by the CCT is most likely the explicit focus of lecturers on addressing conceptual and skills deficiencies. Lecturers of mainstream cohorts often assume that conceptual understanding and process skills have been acquired prior to entrance to university, whereas AD programmes focus specifically on the development of foundation level proficiencies. Our findings in earlier studies have confirmed that this approach was successful, resulting in the more than adequate preparation of $\mathrm{AD}$ students for mainstream chemistry (Potgieter et al., 2008b). It should be noted, however, that the extent of learning gains on more advanced content material covered by the SU mainstream programme was not assessed in this study.

Further insight into conceptual and skills development in mainstream chemistry could be obtained from a detailed analysis of learning gains, as shown in Table 3. In general, first-year chemistry students at SU showed little or no gain in the majority of the problem areas that we have described in Table 1. A small, but meaningful gain was achieved in the very basic aspects of stoichiometry (item 1a), organic chemistry (item 23) and representational competence (items 28 and 29). Significant improvement in the conceptual and skills base of mainstream students at SU (40-50\% gain) occurred only in the topic where lecturers were aware of the lack of background from the secondary level, i.e. in acid-base chemistry (items 13 and 14). This suggests that the introduction of new content material will not necessarily improve poor understanding of the foundational concepts on which they are built. There is a risk that new knowledge may not be assimilated or integrated into flawed prior knowledge structures, which may result in under-performance or failure later. This finding emphasises the importance of alignment of teaching across the secondary-tertiary interface and the important contribution that the CCT can make in this regard.

\section{Conclusions}

In this article we have presented multiple applications of the CCT for diagnostic and prediction purposes. We have shown that the CCT instrument, which was developed initially to describe proficiencies of students entering tertiary studies in chemistry, can be used to monitor levels of preparedness during a period of implementation and refinement of a new curriculum at secondary level. It can also be used for the evaluation of placement policies to ensure that students who need additional support in order to achieve success will have access to appropriate programmes. In addition, the CCT can be used to predict risk of failure in first-year chemistry based on both cognitive and non-cognitive variables as well as to construct conceptual profiles of first-time entering students to inform teaching at the tertiary level. 
Table 3 Gains in conceptual understanding and skills development of the mainstream cohort at SU*.

\begin{tabular}{|c|c|c|c|c|c|c|c|}
\hline \multicolumn{4}{|c|}{ Prevalence $(\%)$} & \multicolumn{4}{|c|}{ Prevalence $(\%)$} \\
\hline Item No. & Pre-test & Post-test & Gain \% & Item No. & Pre-test & Post-test & $\%$ Gain \\
\hline 1a & 59 & 40 & -32 & $17 \mathrm{a}$ & 66 & 71 & 8 \\
\hline $1 \mathrm{~b}$ & 37 & 34 & -8 & $17 b$ & 78 & 76 & 8 \\
\hline 2 & 68 & 61 & -10 & 18 & 40 & 38 & -5 \\
\hline 3 & 61 & 61 & 0 & 19 & 59 & 48 & -19 \\
\hline 4 & 35 & 40 & 14 & $20 \mathrm{a}$ & 74 & 63 & -15 \\
\hline $5 a$ & 44 & 46 & 5 & $20 \mathrm{~b}$ & 80 & 75 & -6 \\
\hline $5 b$ & 46 & 39 & -13 & 21 & 53 & 58 & 9 \\
\hline $6 a$ & 40 & 34 & -15 & 22 & 68 & 59 & -13 \\
\hline $6 \mathrm{~b}$ & 39 & 40 & 3 & 23 & 54 & 41 & -24 \\
\hline 7 & 35 & 28 & -20 & 24 & 33 & 38 & 15 \\
\hline 8 & 51 & 45 & -12 & 25 & 78 & 79 & 1 \\
\hline $9 a$ & 43 & 35 & -19 & 26 & 59 & 59 & 0 \\
\hline $9 b$ & 39 & 31 & -21 & $27 \mathrm{a}$ & 72 & 71 & -1 \\
\hline 10 & 44 & 36 & -18 & $27 \mathrm{~b}$ & 61 & 60 & -2 \\
\hline 11 & 42 & 48 & 14 & 28 & 58 & 44 & -24 \\
\hline 12 & 57 & 57 & 0 & 29 & 56 & 37 & -34 \\
\hline & & & & 30 & 88 & 78 & -11 \\
\hline $13 a$ & 67 & 37 & 45 & 31 & 50 & 46 & -8 \\
\hline $\begin{array}{l}13 a \\
13 b\end{array}$ & 49 & 24 & -51 & $32 \mathrm{a}$ & 70 & 55 & -21 \\
\hline $14 \mathrm{a}$ & 67 & 48 & -28 & $32 \mathrm{~b}$ & 74 & 64 & -14 \\
\hline $14 \mathrm{~b}$ & 54 & 32 & -41 & $33 \mathrm{a}$ & 54 & 45 & -17 \\
\hline 15 & 81 & 64 & -21 & $33 b$ & 61 & 54 & -11 \\
\hline 16 & 76 & 78 & 3 & 34 & 75 & 72 & -4 \\
\hline
\end{tabular}

* Shaded cells represent an improvement of $24 \%$ or more.

Other researchers have designed instruments with similar aims (Mulford and Robinson, 2002); however, the CCT is broader in scope while at the same time being custom-made to probe the South African school-university conceptual interface. It is well known that misconceptions can interfere with learning (e.g. Coștu et al., 2010) thus, while it is useful to know which misconceptions students hold and which concepts students find difficult, the challenge for tertiary educators will be to find ways in which they can promote the development of scientifically accurate conceptions on which to build students' knowledge structures. One option is for lectures to adopt a spiral approach in which material is first presented at basic level and later at a more advanced level. Grove et al. (2008) have reported that using a spiral approach in a course in organic chemistry had a favourable effect on student attrition and learning and prevented overload with respect to the material covered. In most institutions it may not be possible to introduce radical changes in the delivery of material via lectures, thus consideration should be given to the approach by Lodish and Rodriguez (2004) who advocate a combination of lectures and small group tutorials. The latter allow students to engage with material presented in lectures and to construct meaning in a social context. Drawings showing submicro representations are another valuable tool for conceptual development in chemistry (Davidowitz et al., 2010), but they require careful scaffolding (Davidowitz and Chittleborough, 2009, p 180-181) so that students become familiar with them.

Another factor to consider is that good teaching does not guarantee assimilation of concepts by students, as shown by the pre- and post-test data for the mainstream cohort at SU. Lecturers would do well to heed the advice of Laugier and Dumon (2004), who noted that it is unreasonable to expect students "to accomplish without difficulty an intellectual process, which took centuries for scientists to construct.” (p. 327). According to Mulford and Robinson (2002), if students' alternative conceptions are addressed, their understanding of concepts as well as their problem-solving ability may improve.

In this paper we have demonstrated the contribution made by rigorous and systematic assessment of conceptual understanding of chemistry at the secondary-tertiary interface in South Africa. Assessment should not only drive learning; it should also inform teaching, advise instructional reform and contribute towards evidence-based academic administration. The CCT provides a tool that can be applied in all of these spheres both within the discipline of chemistry and for science programmes have chemistry as a key component. An instrument, which was designed for the South African situation, was able to provide more than originally envisaged, namely, to describe entry level proficiencies in tertiary chemistry. It should be possible for other researchers to mould this instrument into their own tailor-made concept inventories to investigate aspects of teaching and learning at the secondary-tertiary interface within their specific contexts.

\section{Acknowledgment}

This material is based upon work supported financially by the National Research Foundation. Any opinion, findings or recommendations expressed in this material are those of the authors, and therefore the NRF does not accept any liability in regard thereto.

Notes

1. In South Africa students study Physical Sciences for Grades 10-12; this subject consists of both Chemistry and Physics 


\section{References}

Ainsworth S., (2006), DeFT: a conceptual framework for considering learning with multiple representations, Learn. Instr., 16, 183-198.

Altink W. M. M. (1987), The evaluation of selection tests for educational upgrading programmes in Botswana and Swaziland, Int. J. Educ. Dev., 7, 1-12.

Barke H.-D., Hazari A and Yitbarek S., (2009), Misconceptions in chemistry, Berlin Heidelberg: Springer-Verlag.

Bond T. G. and Fox C. M., (2007), Applying the Rasch model, New Jersey: Lawrence Erlbaum Associates.

Bowen C. W. and Bunce D. M., (1997), Testing for conceptual understanding in general chemistry, Chem. Educator, 2, 1-17.

Brown T. L., LeMay H. E. and Bursten B. E., (2006), Chemistry: the central science (10th ed.), New Jersey, Pearson: Prentice Hall.

Coștu B., Ayas A. and Niaz M., (2010), Promoting conceptual change in first year students' understanding of evaporation, Chem. Educ. Res. Pract., 11, 5-16.

Davidowitz B., and Chittleborough G., (2009), Linking the Macroscopic and Sub-microscopic Levels: Diagrams, In Gilbert, J. K and Treagust, D. F. (Eds) Multiple representations in chemical education, Dordrecht: Springer, pp.169-191.

Davidowitz B., Chittleborough G. and Murray E., (2010), Student-generated submicro diagrams: a useful tool for teaching and learning chemical equations and stoichiometry, Chem. Educ. Res. Pract., 11, 154-164.

Davidowitz B. and Schreiber B., (2008), Facilitating adjustment to higher education: towards enhancing academic functioning in an Academic Development Programme, S. Afr. J Higher Educ., 22, 191-206.

DeHaan R. L., (2005), The impending revolution in undergraduate science education, J. Sci. Educ. Technol., 14, $253-269$.

Department of Education (DoE), (1998), Education White Paper 4: A Programme for the Transformation of Further Education and Training. Government Gazette, Vol. 399, No. 19281. Pretoria: Government Printer available at

http://www.education.gov.za/dynamic/dynamic.aspx?pageid=329\&catid=12\&category=White\%20papers\&legtype=7, accessed 20 October 2010

Drechsler M. and Van Driel J., (2008), Experienced teachers' pedagogical content knowledge of teaching acid-base chemistry, Res. Sci. Ed., 38, 611-631.

Duit R, (2009), Bibliography STCSE: Students' and Teachers' Conceptions and Science Education, Kiel, available at http://www.ipn.uni-kiel.de/aktuell/stcse/, accessed 31 October 2010 .

Ehrlinger J., (2008), Skill level, self-views and self-theories as sources of error in self-evaluation, Soc. Pers. Psychol. Compass, 2, $382-398$.

Examinations Institute of the American Chemical Society Division of Chemical Education, available at: http://www4.uwm.edu//chemexams/, accessed 31 October 2010 .

Ferguson R. L., (2007), Constructivism and social constructivism, in Bodner, G. M. and Orgill, M. (eds), Theoretical frameworks for research in chemistry / science education, Upper Saddle River: Pearson Prentice Hall, pp. 28-49.

Furió-Más C., Calatayud M-L. and Bárcenas S. L., (2007), Surveying students' conceptual and procedural knowledge of acid-base behavior of substances, J. Chem. Educ., 84, 1717-1724.

Gilbert J. K. and Treagust D. F., (2009), Multiple representations in chemical education. Dordrecht: Springer.

Gramzow R. H., Elliot A. J., Asher E. and McGregor H. A., (2003), Self-evaluation bias and academic performance: some ways and some reasons why, J. Res. Pers., 37, 41-61.

Grayson D., (1996), A holistic approach to preparing disadvantaged students to succeed in tertiary science studies. Part 1. Design of the Science Foundation Programme, Int. J. Sci. Educ., 18, 993-1013.

Grove N. P., Hershberger J. W. and Bretz S. L., (2008), Impact of a spiral organic curriculum on student attrition and learning, Chem.Educ. Res. Pract., 9, 157-162.

Hake R. R., (1998), Interactive-engagement versus traditional methods: a six-thousand-student survey of mechanics test data for introductory physics courses, Am. $J$. Phys., 66, 64-74

Herron J. D., (1975), Piaget for chemists explaining what "good" students cannot understand, J. Chem., Educ., 52, 146-150.

Huddle P. A., White M. D. and Rogers F., (2000), Using a teaching model to correct known misconceptions in electrochemistry, J. Chem., Educ., 77, 104-110. 
Johnstone A. H., (1993), The development of chemistry teaching: a changing response to changing demand, J. Chem. Educ., 70, 701-705.

Koch E., Foxcroft C. and Watson A., (2001), A developmental focus to student access at the University of Port Elizabeth: process and preliminary insights in placement assessment, S. Afr. J Higher Educ., 15, 126-131.

Kousathana M., Demerouti M., and Tsaparlis G., (2005), Instructional misconceptions in acid-base equilibria: an analysis from a history and philosophy of science perspective, Sci. \& Educ., 14, 173-193.

Kruger J. and Dunning D., (1999), Unskilled and unaware of it: how difficulties in recognizing one's own incompetence lead to inflated self-assessments, J. Pers. Soc. Psychol., 77, 1121-1134.

Laugier A. and Dumon A., (2004), The equation of reaction: a cluster of obstacles which are difficult to overcome, Chem. Educ. Res. Pract., 5, $327-342$.

Lodish H. F. and Rodriguez R. F., (2004), A combination of lectures, problem sets and recitation sections is an excellent way to teach undergraduate cell biology at a high level, Cell Biol. Educ., 3, 202-204.

Lubben F., Davidowitz B., Allie S., Buffler A. and Scott I., (2010), Factors influencing access students' persistence in an undergraduate science programme: a South African case study, Int.J. Educ. Dev., 30, 351-358.

Marais P. and Jordaan F., (2000), Are we taking symbolic language for granted? J. Chem. Educ., 77, 1355-1357.

Mayer R .E., (2002), Rote versus meaningful learning, Theor. Pract.,41, 226-232.

McFate C. and Olmsted III, J., (1999), Assessing student preparation through placement tests, J. Chem., Educ., 76, 562-565.

Mulford D. R. and Robinson W. R., (2002), An inventory for alternate conceptions among first-semester General Chemistry students, J. Chem., Educ., 79, $739-744$.

Nakhleh M. B., (1994), Students models of matter in the context of acid-base chemistry, J. Chem. Educ., 71, 495-499.

Ogude A. N. and Bradley J., (1994), Ionic conduction and electrical neutrality in operating electrochemical cells, J. Chem., Educ., 71, $29-34$.

Potgieter M., Davidowitz B. and Blom B., (2005), Chemical Concepts Inventory of first year students at two tertiary institutions in South Africa, Proceedings of the conference of the South African Association of Research in Mathematics, Science and Technology Education, Namibia, January 2005, pp. 664-675.

Potgieter M., Davidowitz B. and Venter E., (2008a), Assessment of preparedness of first-year chemistry students: development and application of an instrument for diagnostic and placement purposes, Afr. J. Res. Math., Sci. Tech. Educ., Special edition, 12, 1-18.

Potgieter M., Davidowitz B. and Mathabatha S. S., (2008b), Preparedness for tertiary chemistry: issues of placement and performance of academic development programmes, S. Afr. J. Higher Educ., 22, 861-876.

Potgieter M., Ackermann M. and Fletcher L., (2010), Inaccuracy of self-evaluation as additional variable for prediction of students at risk of failing first-year chemistry, Chem. Educ. Res. Pract., 11, 17-24.

Potgieter M. and Davidowitz B., (2010), Grade 12 achievement rating scales in the new National Senior Certificate as indication of preparedness for tertiary chemistry, S. Afr. J. Chem., 63, 75-82, http://journals.sabinet.co.za/sajchem/, accessed 31 October 2010.

Russell A. A., (1994), A rationally designed general chemistry diagnostic test, J. Chem. Educ., 71, 314-317.

Sanger M. J. and Greenbowe T. J., (1997), Common student misconceptions in electrochemistry: galvanic, electrolytic, and concentration cells, J. Res. Sci. Teach., 34 $377-398$.

Silberberg M. S., (2009), Chemistry: the molecular nature of matter and change (5th ed.), Boston: McGraw Hill.

Smith K. J., and Metz P. A., (1996), Evaluating student understanding of solution chemistry through microscopic representations, J. Chem., Educ., 73, $233-235$.

Treagust D. F., (1988), Development and use of diagnostic tests to evaluate students' misconceptions in science, Int. J. Sci. Educ., 10, 159-169.

Wagner E. P., Sasser H., and DiBiase W. J., (2002), Predicting students at risk in General Chemistry using pre-semester assessment and demographic information, $J$. Chem., Educ., 79, 749-755. 